\title{
$\widehat{A}$ Madridge \\ madridge Journal of Nursing
}

Interconnecting Scientific World

Research Article

Open Access

\section{SBIRT and MI Training among School Nurses and Psychiatric Mental Health Nurse Practitioner Students: A Pilot Study of Competency and Acceptability}

\author{
Kimberly A Williams ${ }^{1 *}$, Candice N Selwyn ${ }^{1}$, Michele Wilmoth ${ }^{2}$, and Katherine Bydalek ${ }^{1}$ \\ ${ }^{1}$ College of Nursing, University of South Alabama, USA \\ ${ }^{2}$ School Health Services, Akron Children's Hospital, USA
}

Article Info

*Corresponding author:
Kimberly A Williams
Associate Professor
College of Nursing
University of South Alabama
USA
Tel: 330-389-0539
E-mail: kwilliams@southalabama.edu

Received: December 12, 2020

Accepted: January 22, 2021

Published: January 29, 2021

Citation: Williams KA, Selwyn CN, Wilmoth M, Bydalek K. SBIRT and MI Training among School Nurses and Psychiatric Mental Health Nurse Practitioner Students: A Pilot Study of Competency and Acceptability. Madridge J Nurs. 2021; 6(1): 173-179. doi: 10.18689/mjn-1000131

Copyright: @ 2021 The Author(s). This work is licensed under a Creative Commons Attribution 4.0 International License, which permits unrestricted use, distribution, and reproduction in any medium, provided the original work is properly cited.

Published by Madridge Publishers

\begin{abstract}
Adolescent substance use and psychological disorders have increased across the U.S. Inclusion of school nurses trained in screening, brief intervention, and referral for treatment (SBIRT) and motivational interviewing (MI) may improve screening for mental health disorders among adolescents. Furthermore, graduate psychiatric nurse practitioner students trained in $\mathrm{Ml}$ who are placed in schools can offer $\mathrm{Ml}$ under supervision, an initial step towards building integrated health care in schools. This retrospective/prospective pilot study in a Midwest City in the United States sought to determine the acceptability of SBIRT and MI training among school nurses and psychiatric nurse practitioner student nurses. Twenty-five school nurses and three nurse practitioner students participated in SBIRT and MI training. Sixty-four percent $(n=18)$ responded to a survey on acceptability. Of these, $38 \%(n=7)$ allowed assessment of their Motivational Interviewing Treatment Integrity competency forms demonstrating competency with an aggregate score of 3.97 out of 5 competency rating at the end of training. Follow-up surveys sent to participants post-training indicated continued use and acceptability of SBIRT and MI after training.
\end{abstract}

Keywords: SBIRT; Motivational interviewing; School nurses.

\section{Introduction}

School nurses regularly encounter adolescences with substance use problems, including the use of opioids. In addition, adolescents have struggled with substance use and adolescent substance use continues to remain steady. In 2017, approximately 50 percent of teenagers in the U.S. have missed used substances and $85 \%$ know of someone using substances during school hours [1]. The National Adolescent Drug Trends 2019 findings noted that the annual prevalence for substance use was $15 \%$ for $8^{\text {th }}$ graders, $31 \%$ for 10 graders and $38 \%$ for $12^{\text {th }}$ graders with vaping marijuana and vaping nicotine showing the most significant increases [2]. Substance use is associated with the risk of depression, anxiety, and suicidality, negatively affecting school performance and relationships [3,4]. Given these issues, schools are vital in identifying substance use and other mental health problems among children and adolescents $[5,6]$. The Federal Commission on School Safety [5] has suggested that providing mental health support early in childhood has much better outcomes than later in life. They also recommend that mental health care be accessible through school-based integrated health care. Considering this report's findings, one possible approach to address this need could be achieved by providing training in screening brief intervention and referral to treatment (SBIRT) along with motivational interviewing (MI) to school nurses and continued support 
through school-based integrated health. This article describes SBIRT and MI training of school nurses and psychiatric nurse practitioner students along with the competency and feasibility of SBIRT and MI in the Midwest U.S.

\section{Background}

Initially created for use within a primary care setting to address substance use, SBIRT is easily implemented using three steps: (1) use of reliable tools to screen for the potential presence of a disorder(s); (2) use of a brief intervention, such as Motivational Interviewing (MI), to increase motivation for treatment of the disorder(s); and (3) referral for further evaluation and follow-up treatment. This comprehensive, patient-focused approach can consist of up to five sessions lasting from 5 to 30 minutes [7]. Implementation of SBIRT and $\mathrm{MI}$ have resulted in healthy behavior changes for adolescents in not only psychiatric settings, but also in middle and high school settings, with students demonstrating significant reductions in substance use post intervention [8-12].

Given SBIRT's positive results in schools, some states have implemented SBIRT within their schools to address adolescent substance use [10]. Although schools have begun to utilize SBIRT, its acceptance as a school-based model of intervention may be slow. A study by Harris Shaw and colleagues [13] surveyed 16 school-based clinics in New York State to understanding their use of SBIRT. Of the $162,40 \%(n=64.8)$ responded to the survey, and only $22 \%(n=14)$ reported practicing SBIRT [13]. In addition, schools utilizing the SBIRT model, commonly referred adolescents who screen positive for a given disorder to an outside agency for treatment. Outside referrals may result in significant barriers to treatment and follow-up due to the need for absence from school, transportation, and cost of specialty care. Such barriers may contribute to the finding by the Centers for Disease Control that only $20 \%$ of children with mental health disorders obtain psychiatric care [14].

\section{Applying $\mathrm{MI}$ in schools}

The goal of $\mathrm{Ml}$ is to use a patient-centered approach in the discussion of values that help a person to move towards behavior change. The MI process uses open-ended questions, reflective statements, and avoids the use of the word "but" as it tends to have a negative connotation. Components of $\mathrm{MI}$ consist of collaboration, evocation, and autonomy [3,15-17]. School nurses can apply these components when they are providing the results of any screening to students. Start with collaboration by using positive and nonjudgmental communication encouraging an adolescent to express their experiences and/or perspective. For example, "I wanted to share with you the results of the screening tool you turned in about drug use, do you mind if I share them with you?" This statement using a nonjudgmental tone conveys a willingness to be partners (collaborating) from the start. Continue with providing the results of the screening: "I noticed that you indicated you occasionally drink with friends," and move into evocation. Evocation is the ability of the person to express their feeling and/or motivations for changing a specific behavior. Evocations can begin with asking the student how they feel about the results of the screening or what they think may the reason for the positive screening result. "I am wondering how you feel about the results". There may be a need for a little silence to give the person some time to think about what you said. If there is no answer after a period of a few minutes, you can ask them to share some of the good things they experience when they drink and then ask about some of the bad things. This can evoke some negative aspects they experienced and can become the foundation to build on for motivating the adolescent to seek treatment. For example, "Let me make sure I understand you. When you drink, you feel cool and get to have fun with your friends, and you have experienced some issues with getting in trouble with friends when they were driving drunk and your parents had to go to the police station to pick you up. You also mentioned that you were an A and B student and your grades have been dropping to Cs and Ds. Did I get this correct?" Then give time for the person to confirm or correct your understanding. This process is called a reflection. Once confirmed or corrected, follow up with another reflection: "It seems that there are more bad things that can happen with drinking than good things. What do you think about what I just said?" If the adolescent disagrees, they may not be ready for change and you can let them know to "please come back any time they want to come back to talk about their drinking". If they agree, ask them where they think they are with getting help at this moment on a scale of 0 to 10 (10 definitely stopping or getting help and 0 not ready for help at all). Follow this by asking why there are not lower (pick a couple of numbers lower than their answer). This helps them to look at positive aspects like their support systems and so on. Then ask the adolescent if they would like to begin discussing a plan for change that includes a referral.

The success of $\mathrm{Ml}$ is related to the autonomy it gives to adolescents to make their own decisions about changing behaviors. Importantly, MI works from the premise that it is normal for an adolescent to resist the idea of change. The use of a positive approach for asking permission to share information about current behaviors and discussion of values important to the adolescent can result in positive change. Use of $\mathrm{MI}$ has been successful in adolescents for substance use, medication adherence, physical activity and more $[3,8,9,11,14,15]$. However, $\mathrm{Ml}$ in the context of SBIRT is considered very brief, lacking the time needed to help adolescents change risky behaviors and sustain healthier behaviors. In this case, adolescents often require referrals for more specialized care such as additional MI sessions needed to enhance the likelihood of changing and sustaining healthier behaviors. The purpose of this pilot study was to determine the acceptability of a combined SBIRT and MI training among school nurses and PMHNP student nurses with the goal of reducing barriers that interfere with adolescents receiving needed care. 


\section{Methods}

Institutional Review Board of a children's hospital located in the Midwest gave permission to conduct this pilot study (No XXXXXXX) of school nurses employed by a local children's hospital and PMHNP students enrolled in a psychiatric mental health nurse practitioner practicum at a university located in a Midwest City in the United States. The IRB granted permission to include the evaluation of the competency and acceptability survey from a training retrospectively that took place in 2017 as well as data obtain from training prospectively that took place in 2018. The pilot study consisted of an evaluation of MI competency post training as well as SBIRT and MI acceptability for school nurses and PMHNP students. Inclusion criteria for nurses were adults who were 1) school nurses employed by a local children's hospital (in this Mid-West state many schools contract with hospitals to provide school nurse care) and nurses who were enrolled in a psychiatric mental health nurse practitioner practicum class and obtaining a practicum experience within the school setting at a local university, and 2) who signed up to attend a SBIRT and MI two-day training workshop. After attending the workshop, a Survey Monkey link was sent to the email of each school nurse and PMHNP students who had attended the SBIRT and MI training workshops. Consent to review the past competency evaluation forms and to participate in the survey to assess the acceptability of using SBIRT and MI were obtained through the survey.

\section{Measures}

At the time of this pilot study, evaluation of SBIRT competency was in its infancy and validated evaluation tools were not readily available. However, the Motivational Interviewing Treatment Integrity Code (MITI) [18] was available and was used to evaluate Ml skills competency. The simple competency coding form consisted of two areas of evaluation. First, a global rating section evaluated the competence of the trainee on a Likert scale from low (1) to high (5) in five dimensions of MI. Second, the area required a count of trainee's ability to use Ml including simple reflections, complex reflections, open-ended questions, and $\mathrm{MI}$ adherence. Competency for $\mathrm{Ml}$ was demonstrated by participants achieving an average score of 4 on the global clinical ratings section, attainment of two to one for the ratio of simple reflections, attainment of $50 \%$ for complex reflections, attainment of $70 \%$ for open-ended questions, and attainment of $100 \%$ for $\mathrm{MI}$ adherence. The MITI has been found to have good-to-excellent inter-rater reliability with Interclass Correlation Coefficient (ICC) scores of 0.72 and 0.71 in evaluation of empathy and MI spirit along with ICC scores of 0.83 to 0.98 in the other areas evaluated for successful training [19].

Acceptability of school based SBIRT and MI was evaluated using a self-report survey. The survey consisted of 9 demographics questions; 12 questions ranked from strongly disagree, disagree, neutral, agree and strongly agree; and one open-ended question (Tables 1 and 2). These questions asked participants their opinion about over all acceptability of SBIRT in nursing and in schools and use of $\mathrm{Ml}$ in nursing.

Table 1. Frequency of Demographic Questions.

\begin{tabular}{|c|c|c|c|}
\hline Total Responses & Answer & Frequency & Percentage \\
\hline \multirow{2}{*}{$\begin{array}{c}\text { Gender } \\
N=18\end{array}$} & Female & 16 & $88.9 \%$ \\
\hline & Male & 2 & $11.1 \%$ \\
\hline \multirow{9}{*}{$\begin{array}{l}\text { Age range } \\
\qquad N=18\end{array}$} & $19-25=1$ & 1 & $5.6 \%$ \\
\hline & $26-30=3$ & 3 & $16.7 \%$ \\
\hline & $31-35=2$ & 2 & $11.1 \%$ \\
\hline & $36-40=2$ & 2 & $11.1 \%$ \\
\hline & $41-45=4$ & 4 & $22.2 \%$ \\
\hline & $46-50=1$ & 1 & $5.6 \%$ \\
\hline & $51-55=2$ & 2 & $11.1 \%$ \\
\hline & $56-60=1$ & 1 & $5.6 \%$ \\
\hline & $\geq 61=2$ & 2 & $11.1 \%$ \\
\hline $\begin{array}{l}\text { Ethnic/racial background } \\
\qquad N=18\end{array}$ & Caucasian & 18 & $100 \%$ \\
\hline \multirow{3}{*}{$\begin{array}{l}\text { Highest degree } \\
\quad N=18\end{array}$} & Associate & 2 & $11.1 \%$ \\
\hline & Baccalaureate & 11 & $61.1 \%$ \\
\hline & Masters & 5 & $27.8 \%$ \\
\hline \multirow{5}{*}{$\begin{array}{l}\text { Employed in nursing } \\
\qquad N=17\end{array}$} & $<5 \mathrm{yrs}$ & 6 & $35.3 \%$ \\
\hline & 5 to $10 \mathrm{yrs}$ & 6 & $35 \%$ \\
\hline & $16-20$ yrs & 1 & $5.9 \%$ \\
\hline & $21-25 \mathrm{yrs}$ & 1 & $5.9 \%$ \\
\hline & $>25 \mathrm{yrs}$ & 3 & $17.6 \%$ \\
\hline \multirow{5}{*}{$\begin{array}{l}\text { How long have you been a } \\
\text { school nurse? } \\
N=14\end{array}$} & $<5 \mathrm{yrs}$ & 8 & $57.2 \%$ \\
\hline & $5-10$ yrs & 3 & $21.5 \%$ \\
\hline & $11=15 \mathrm{yrs}$ & 1 & $7.1 \%$ \\
\hline & $21-25 \mathrm{yrs}$ & 1 & $7.1 \%$ \\
\hline & $26-30 \mathrm{yrs}$ & 1 & $7.1 \%$ \\
\hline \multirow{4}{*}{$\begin{array}{l}\text { What types of school do } \\
\text { you or have you worked } \\
\text { in? Mark all that apply } \\
\qquad N=14\end{array}$} & Elementary & 1 & $71 \%$ \\
\hline & Middle school & 2 & $14.2 \%$ \\
\hline & High school & 4 & $28.6 \%$ \\
\hline & All of the above & 10 & $71.5 \%$ \\
\hline \multirow{3}{*}{$\begin{array}{l}\text { The school you are } \\
\text { currently employed is } \\
\text { considered: } \\
N=14\end{array}$} & Suburban & 8 & $57.2 \%$ \\
\hline & Rural & 2 & $14.2 \%$ \\
\hline & $\begin{array}{l}\text { Other (specified } \\
\text { as float nurse) }\end{array}$ & 4 & $28.6 \%$ \\
\hline
\end{tabular}

\section{Procedure}

Because training included an evaluation of videotaped $\mathrm{MI}$ sessions by a clinical psychologist who was an expert in $\mathrm{MI}$, the number of participants was limited to 16 or less for each training session. The sample consisted of school nurses $(n=25)$ and psychiatric mental health nurse practitioner (PMHNP) students $(n=3)$ enrolled in a practicum class and obtaining a practicum experience within the school setting. Participants were trained in SBIRT and MI using a PowerPoint presentation, followed by a discussion on communication styles and each phase of $\mathrm{Ml}$, along with role-playing. Both trainings were conducted by the same person who was a MITI trainer and 
$\mathrm{PhD}$ Clinical Psychologist with 30 years of $\mathrm{MI}$ and SBIRT expertise. Training consisted of two days lasting 6 hours each day. Participants in the training were placed in groups of two at the end of the PowerPoint presentation and discussions. They participated in role-play exercises while videotaping each other in the role of the nurse using $\mathrm{Ml}$ and the role of a patient presenting with an unhealthy behavior to change. Videos were returned to the instructor who then reviewed and evaluated the competency of the participants using the MITI form. Then a Survey Monkey link to the acceptability survey was sent (Table 2). Because the researchers were awaiting IRB approval to allow distribution of the acceptability survey, the first group of nurses received the survey link six months after attending the training. The second group of nurses received the survey link one month after attending the SBIRT Training.

Table 2. Distribution of MI Competency Scores.

\begin{tabular}{|c|c|}
\hline Frequency & MITI Global Score \\
\hline 1 & 3.625 \\
\hline 2 & 3.75 \\
\hline 1 & 3.876 \\
\hline 2 & 4.0 \\
\hline 1 & 4.125 \\
\hline $\mathrm{N}-7$ & Mean Score \\
& 3.967 \\
\hline
\end{tabular}

\section{Data analysis}

Data analysis was achieved by entering data into a data file in the IBM SPSS ${ }^{\circledR}$ Statistics for Windows, Version 25 [19]. Scoring of the MITI for school nurses and psychiatric nurse practitioner students was analyzed using mean values and reported an aggregated percentage. Data analysis for acceptability of SBIRT/MI training used descriptive statistics reported as aggregate data.

\section{Results}

Twenty-eight nurses attended SBIRT/MI training, 25 school nurses and 3 PMHNP student nurses enrolled in a practicum class and obtaining a practicum experience within the school setting. Of these, 18 (64\%) agreed to participate in the acceptability survey. For participant age ranges, educational levels, years in nursing, and years in school nursing (Table 3). All participants were Caucasian (Table 3). Approximately $89 \%$ of the participants were female. Of the participants, the majority held baccalaureate degrees, worked in all levels of schools, and had been employed as a school nurse for less than 5 years (Table 3).

Table 3. Feasibility Questions and Responses.

\begin{tabular}{|c|c|c|c|}
\hline Feasibility Questions & $\begin{array}{c}\text { Total } \\
\text { Responses }\end{array}$ & Frequency & Percentage \\
\hline $\begin{array}{c}\text { The use of SBIRT is } \\
\text { appropriate for nurses } \\
\text { who are practicing in any } \\
\text { nursing setting. }\end{array}$ & $N=18$ & Agree=8 & $44.5 \%$ \\
\cline { 3 - 4 } & & $\begin{array}{c}\text { Strongly } \\
\text { agree=10 }\end{array}$ & $55.5 \%$ \\
\hline
\end{tabular}

\begin{tabular}{|c|c|c|c|}
\hline \multirow{2}{*}{$\begin{array}{l}\text { The use of SBIRT is } \\
\text { appropriate for nurses } \\
\text { who are practicing in } \\
\text { school settings. }\end{array}$} & \multirow[t]{2}{*}{$N=18$} & Agree $=8$ & $44.5 \%$ \\
\hline & & $\begin{array}{c}\text { Strongly } \\
\text { agree }=10\end{array}$ & $55.5 \%$ \\
\hline \multirow{3}{*}{$\begin{array}{l}\text { Ml is an appropriate } \\
\text { therapy for nurses who } \\
\text { are practicing in any } \\
\text { nursing setting. }\end{array}$} & \multirow[t]{3}{*}{$N=18$} & $\begin{array}{l}\text { Neither agree } \\
\text { or disagree }=1\end{array}$ & $5.6 \%$ \\
\hline & & Agree $=6$ & $33.3 \%$ \\
\hline & & $\begin{array}{l}\text { Strongly } \\
\text { agree=11 }\end{array}$ & $61.1 \%$ \\
\hline \multirow{3}{*}{$\begin{array}{l}\text { After completing my } \\
\text { training, I felt comfortable } \\
\text { in my ability to use Ml/ } \\
\text { Brief } \mathrm{Ml} \text { in my practice. }\end{array}$} & \multirow[t]{3}{*}{$N=18$} & $\begin{array}{l}\text { Neither agree } \\
\text { or disagree }=2\end{array}$ & $11.1 \%$ \\
\hline & & Agree $=12$ & $66.7 \%$ \\
\hline & & $\begin{array}{l}\text { Strongly } \\
\text { agree }=4\end{array}$ & $22.2 \%$ \\
\hline \multirow{4}{*}{$\begin{array}{l}\text { I feel that I need more } \\
\text { training for me to be } \\
\text { comfortable in using } \mathrm{Ml} / \\
\text { Brief } \mathrm{Ml} \text {. }\end{array}$} & \multirow[t]{4}{*}{$N=18$} & Disagree $=1$ & $5.6 \%$ \\
\hline & & $\begin{array}{c}\text { Neither agree } \\
\text { or disagree }=10\end{array}$ & 55.5 \\
\hline & & Agree $=6$ & $33.3 \%$ \\
\hline & & $\begin{array}{l}\text { Strongly } \\
\text { agree }=1\end{array}$ & $5.6 \%$ \\
\hline \multirow{4}{*}{$\begin{array}{l}\text { I feel comfortable in using } \\
\text { MI/Brief MI but I would } \\
\text { like to practice MI with } \\
\text { someone. }\end{array}$} & \multirow[t]{4}{*}{$N=18$} & Disagree=1 & $5.6 \%$ \\
\hline & & $\begin{array}{l}\text { Neither agree } \\
\text { or disagree }=8\end{array}$ & $44.5 \%$ \\
\hline & & Agree $=6$ & $33.3 \%$ \\
\hline & & $\begin{array}{l}\text { Strongly } \\
\text { agree }=3\end{array}$ & $16.6 \%$ \\
\hline \multirow{3}{*}{$\begin{array}{l}\text { I would like to have the } \\
\text { opportunity to discuss } \\
\text { how to use an MI } \\
\text { approach with past/ } \\
\text { current situations. }\end{array}$} & \multirow[t]{3}{*}{$N=18$} & Disagree $=4$ & $22.2 \%$ \\
\hline & & $\begin{array}{l}\text { Neither agree } \\
\text { or disagree }=8\end{array}$ & $44.5 \%$ \\
\hline & & Agree $=6$ & $33.3 \%$ \\
\hline \multirow{4}{*}{$\begin{array}{l}\text { I would like to have } \\
\text { biannual training for } \\
\text { SBIRT/MI. }\end{array}$} & \multirow[t]{4}{*}{$N=18$} & Disagree $=3$ & $16.6 \%$ \\
\hline & & $\begin{array}{l}\text { Neither agree } \\
\text { or disagree }=5\end{array}$ & $27.8 \%$ \\
\hline & & Agree $=7$ & $39.0 \%$ \\
\hline & & $\begin{array}{l}\text { Strongly } \\
\text { agree }=3\end{array}$ & $16.6 \%$ \\
\hline \multirow{4}{*}{$\begin{array}{l}\text { I would like to have } \\
\text { annual training for SBIRT/ } \\
\text { MI. }\end{array}$} & \multirow[t]{4}{*}{$N=18$} & Disagree $=4$ & $22.2 \%$ \\
\hline & & $\begin{array}{l}\text { Neither agree } \\
\text { or disagree }=5\end{array}$ & $27 . \%$ \\
\hline & & Agree $=7$ & $39.0 \%$ \\
\hline & & $\begin{array}{l}\text { Strongly } \\
\text { Agree }=2\end{array}$ & $11.1 \%$ \\
\hline \multirow{2}{*}{$\begin{array}{c}\text { Since my training, I have } \\
\text { used MI/Brief Ml in my } \\
\text { practice. }\end{array}$} & \multirow[t]{2}{*}{$N=17$} & Yes $=15$ & $88.1 \%$ \\
\hline & & $\mathrm{No}=2$ & $11.8 \%$ \\
\hline \multirow{3}{*}{$\begin{array}{l}\text { Since my training, MI has } \\
\text { changed the way I } \\
\text { approach my patient/s, } \\
\text { parent/guardian/s, } \\
\text { colleagues, and/or school } \\
\text { personnel. }\end{array}$} & \multirow[t]{3}{*}{$N=18$} & $\begin{array}{l}\text { Neither agree } \\
\text { or disagree }=1\end{array}$ & $5 / 6 \%$ \\
\hline & & Agree $=15$ & $83.3 \%$ \\
\hline & & $\begin{array}{l}\text { Strongly } \\
\text { Agree }=2\end{array}$ & $11.1 \%$ \\
\hline \multirow[t]{2}{*}{$\begin{array}{l}\text { I do not feel SBIRT/MI is } \\
\text { useful in my practice. }\end{array}$} & \multirow[t]{2}{*}{$N=18$} & $\begin{array}{c}\text { Strongly } \\
\text { disagree=10 }\end{array}$ & $55.5 \%$ \\
\hline & & Disagree $=8$ & $44.5 \%$ \\
\hline
\end{tabular}




\section{Discussion}

While the findings of this pilot study are limited due to the low number of participants, they provide a foundation for further work to support the value of SBIRT and MI training among both school nurses and PMHNP students obtaining a practicum experience within the school setting. Furthermore, it was noted that both school nurses and psychiatric nurse practitioner students that participated were trained and competent in $\mathrm{Ml}$ in a relatively short time. The participants in this pilot study indicated the use of SBIRT and $\mathrm{MI}$ was appropriate within the school setting, as $88 \%(n=16)$ of respondents continued to use $\mathrm{Ml}$ in their practice after training.

\section{Limitations}

As mentioned above limitations of this pilot study were related to the number of participants and impacted in the ability to fully measure SBIRT and MI competency as well as determining acceptability. Factors contributing to the limited number of School Nurses and PMHNP students were due to the limited number of nurses that could be trained each session and conducting two trainings (one per year). In addition, the limited number of clinical placements of PMHNP students within the school setting impacted the number of PMHNP students that could be trained. Therefore, it is recommended that future studies include more frequent training opportunities to improve recruitment throughout the study. Additionally, it is suggested that training be offered to all PMHNP students regardless of clinical placement. This training could be accomplished by increasing accessibility could through live sessions, virtual sessions, and on-demand webinars. Competency evaluation could be accomplished not only through recorded role play with partners during training session, but also virtually or through simulations post training.

Limitations for evaluating competency most likely were related to the process for consenting. Participants were asked to provide their name on the acceptability survey if they consented to allow researchers to evaluate their MITI competency results. Only seven nurses provided their names while the remaining participants skipped this option. It is also possible that theses seven nurses received feedback from their evaluation reflecting that they were competent in $\mathrm{MI}$ compared to those who did not provide their name to allow the researchers to obtain their MITI competency score or those that did not participate in the acceptability survey. A larger number of participants may have resulted in either lower or higher competency findings. Suggestion to reduce this limitation may be obtain permission to obtain the MITI scores on the day participants record their MI role play videos, to assign participant numbers for participants completing the survey, and/or to design the survey requiring a response for allowing researchers to obtain competency scores.

Additionally, there were limitations for the inability to evaluate SBIRT competency. At the time of this pilot study's IRB approval, no assessment tools for evaluating SBIRT competency existed and present a limitation in evaluating the competency of participants' ability to follow the steps in the process of SBIRT. Since this study, the SBIRT checklist for observation in real-time (SCORe) [20] was developed in 2017 to assess adherence to SBIRT. The researchers trained 18 judges to evaluate providers. Seventy-six providers were observed and evaluated performing SBIRT in three types of settings: emergency departments $(n=10)$, hospital outpatient/ambulatory clinics $(n=16)$ and hospital in-patient settings $(n=5)$. They found that across programs more than half of providers adhered to SBIRT. Fifty-six percent adhered to screening ( $n=43), 54 \%(n=41)$ adhered to brief intervention, and $53 \%(n=40)$ of referral to treatment elements. Additionally, they measured adherence to $\mathrm{Ml}$ skills based on the components of FRAMES (Feedback, Responsibility, Advice, Menu of options, Empathy, Self-efficacy) within the SCORe checklist. The authors found that of the 41 providers adhered to brief intervention, $81 \%(n=33)$ included the components of FRAMES. Overall, the SCORe was found to be a flexible method for assessing adherence to evidence based SBIRT protocols. We suggest including the use of the SCORe along with the MITI to assess adherence to SBIRT and competency of $\mathrm{Ml}$ post training.

Only 18 out of 28 nurses participated in the acceptability survey; the results for the acceptability of SBIRT and MI may have been different had all 28 nurses participated in the survey lending to self-selection bias. One speculation for the low number of participants may have been related to the fact that the survey was totally anonymous so there were no emails or personal identifying information collected. Therefore, participants were asked to consent to the survey and provide their name if they would allow their $\mathrm{MI}$ competency score to be evaluated by researchers. The method of recruitment also lent itself to self-selection bias. One suggestion to reduce these limitations is to recruit participants and obtain permission to evaluate competency scores at the time of the training rather than through emailed surveys after the training is over. The timing between administering the training and the survey for each group was different as the first group of school nurses was sent the link for the survey retrospectively (six months) after training, while the second group was sent a link to the survey one month after training. This discrepancy could have impacted the findings for acceptability for using SBIRT and MI.

To improve the understanding of acceptability in increase the significance; a mix methods approach could be implemented that included not only surveying participants, but also include focus groups or follow up interviews. Although the pilot study focused on acceptability through perceptions and beliefs, the low response rate to the survey appeared to give initial insight of some barriers related to feasibility. While nurse's beliefs about SBIRT and MI can influence their adoption of SBIRT and Ml, more studies would need to be implemented to measure the feasibility of including SBIRT and MI in practice. For example, questions should focus on SBIRT and MI as it relates to time and effort, nursing role, recruitment and retention. Considering these 
limitations and findings, further studies are needed to evaluate not only acceptability and feasibility but also the competency of SBIRT as there few studies that measure specific competency. Along with SBIRT competency, evaluation of MI competency as a part of the Brief Intervention aspect of SBIRT as this is an integral part of motivation a person to seek help to change unhealth behaviors.

\section{Other considerations}

Planning for training is a must as training times for SBIRT and $\mathrm{MI}$ can be a barrier for many school nurses given the time needed for presenting the content and for videotaping their role-play. Also, the number of attendees for the training was limited due to the time needed for the instructor to review and evaluate each video from the role-play session. However, the workshops had almost full attendance as they were conducted in the summer when the majority of schools are closed, and the majority of school nurses were available to attend. Therefore, it is recommended that researchers work closely with school nurse administrators and supervisors to schedule the best days and times for SBIRT and MI training.

\section{Implications to Nursing}

This study presents important implications for school nurses, psychiatric mental health nurse practitioner programs and school health communities. School nurses have day-today contact with most of the children in the community. This contact is optimal for allowing successful delivery of SBIRT and $\mathrm{MI}$ within this setting. Additionally, school nurses conduct routine screening for students frequently providing both students and their parents with follow-up care outside of the school.

As previously mentioned, the components of SBIRT are: (1) use of reliable tools to screen for the potential presence of a disorder(s); (2) use of a brief intervention such as MI to increase motivation for treatment of the disorder(s); and (3) referral for further evaluation and treatment. School nurses are accustomed to the screening and referral process consistent with SBIRT. However, the approach taken between screening and referral may possibility result in loss to followup. The sequela of students and parents not following through with referrals can lead to poor health outcomes and possibly involvement of child services. Therefore, use of brief $\mathrm{Ml}$ in the context of SBIRT that is aimed at making behavior changes may be the best approach to apply in school settings.

By including a SBIRT and MI approach in their practice along with affiliations between schools and colleges/ universities offering clinical sites for training PMHNP students, school nurses can significantly impact a child's medical health, mental health, and future outcomes. The success of this study was achieved by the collaboration of a university nursing school, a hospital that offered school nurse services to the local school, and a local school. It is recommended that school nurse researchers consider studies building similar collaborations and include mental health faculty, school nurses, PMHNP students, school superintendents, school guidance counselors, teachers, other school mental health providers and local community mental health services. Future collaborations at this level can improve the existing data and reduce barriers for the use of SBIRT and $\mathrm{MI}$ and improving access to mental health care for adolescents.

\section{Acknowledgements}

None.

\section{Conflict of Interest Statement}

The authors have no conflict of interest.

\section{Funding}

Kimberly A. Williams received a Board of Directors Research Grant from the International Nurses Society on Addictions.

\section{References}

1. NCDAS. Drug Use among Youth: Facts and Statistics. National Center for Drug Abuse Statistics. 2020.

2. University of Michigan. National Adolescent Drug Trends in 2019: Finding Released. Monitoring the Future. 2020.

3. Brown RA, Abrantes AM, Minami $\mathrm{H}$, et al. Motivational interviewing to reduce substance use in adolescents with psychiatric comorbidity. J Subst Abuse Treat. 2015; 59: 20-29. doi: 10.1016/j.jsat.2015.06.016

4. Jones CM, Clayton HB, Depurty NP, et al. Prescription Opioid Misuse and Use of Alcohol and Other Substances among High School Students-Youth Risk Behavior Survey, United States, 2019. MMWR. 2020: 69(1): 38-46. doi: 10.15585/mmwr.su6901a5

5. Federal Commission on School Safety. Final Report of the Federal Commission on School Safety. 2020.

6. SAMHSA. School and Campus Health. Substance Abuse and Mental Health Services Administration. 2020.

7. SAMHSA. SBIRT: Screening, brief intervention, and referral to treatment. SAMHSA-HRSA Center for Integrated Health Solutions. 2020.

8. Dean S, Britt E, Bell E, Stanley J, Collings S. Motivational interviewing to enhance adolescent mental health treatment engagement: $A$ randomized clinical trial. Psycho Med. 2016; 46(9): 1961-1969. doi: 10.1017/S0033291716000568

9. Markland D, Ryan R, Tobin V, Rollnick S. Motivational interviewing and self-determination theory. J Soc Clin Psychol. 2005; 24(6): 811-831. doi: 10.1521/jscp.2005.24.6.811

10. MASBIRT TTA. SBIRT in schools. Boston Medical Center. 2020.

11. Stewart DG, Felleman BI, Arger CA. Effectiveness of motivational incentive for adolescent marijuana use in a school-based intervention. J Subst Abuse Treat. 2015; 58: 43-50. doi: 10.1016/j. jsat.2015.06.002

12. Wisconsin Safe \& Healthy Schools Center. School SBIRT-screening brief intervention, referral to treatment. Wisconsin Safe \& Healthy Schools Training \& Technical Assistance Center. 2020.

13. Harris BR, Shaw BA, Sherman BR, Lawson HA. Screening, brief intervention, and referral to treatment for adolescents: Attitudes, perceptions, and practice of New York school-based health center providers. Subst Abus. 2016; 37(1): 161-167. doi: 10.1080/08897077.2015.1015703

14. CDC. Children's Mental Health: Improving Access to Children's Mental Health Care. Center for Disease Control and Prevention. 2018. 
15. Bonde $A H$, Bentsen $\mathrm{PB}$, Hindhede AL. School nurses' experiences with motivational interviewing for preventing childhood obesity. J Sch Nurs. 2014; 30(6): 448-455. doi: 10.1177/1059840514521240

16. Curtis BL, McLellan AT, Gabellini BN. Translating SBIRT to public school settings: An initial test of feasibility. J Subst Abuse Treat. 2014; 46(1): 15-21. doi: 10.1016/j.jsat.2013.08.001

17. Williams KA, Monsman $\mathrm{H}$, Chadwell J. Why Do Adolescents' Engage in Non-Suicidal Self-Injurious Behaviors? How nurses can screen, intervene and provide appropriate referrals. American Nurse Today. 2018; 13(8): 37-40.
18. Owens MD, Rowell LN, Moyers T. Psychometric properties of the Motivational Interviewing Treatment Integrity coding system 4.2 with jail inmates. Addict Behav. 2017; 73: 48-52. doi: 10.1016/j. addbeh.2017.04.015

19. IBM SPSS Statistics for Windows, Version 25.0. Armonk, NY: IBM Corp.

20. Vendettie JA, McRee BG, Del Boca FK. Development of the SBIRT checklist for observation in real-time (SCORe). Addiction. 2017; 112(2): 34-41. doi: 10.1111/add.13657 